Published in final edited form as:

Int J Radiat Oncol Biol Phys. 2019 May 01; 104(1): 67-74. doi:10.1016/j.ijrobp.2018.12.050.

\title{
Three-Fraction Accelerated Partial Breast Irradiation (APBI) Delivered With Brachytherapy Applicators Is Feasible and Safe: First Results From the TRIUMPH-T Trial
}

\author{
Atif J. Khan, MD ${ }^{\star}$, , Peter Y. Chen, MD ${ }^{\ddagger}$, Catheryn Yashar, MD§, Matthew M. Poppe, MD $\|$, \\ Linna Li, MDI, Zeinab Abou Yehia, $\mathbf{M D}^{\dagger}$, Frank A. Vicini, MD\#, Dirk Moore, $\mathbf{P h D}^{\dagger}$, Roger \\ Dale, $\mathrm{PhD}^{* *}$, Doug Arthur, MD ${ }^{\dagger \dagger}$, Chirag Shah, MD ${ }^{\ddagger}$, Bruce G. Haffty, $\mathrm{MD}^{\dagger}$, Robert Kuske, \\ MD§§ \\ *Memorial Sloan Kettering Cancer Center, New York, New York \\ †Michigan Healthcare Professionals, 21st Century Oncology, Farmington Hills, Michigan \\ ‡Beaumont Health System, Royal Oak, Michigan \\ §University of California San Diego/Moores Cancer Center, La Jolla, California \\ \| Huntsman Cancer Institute, Salt Lake City, Utah \\ "Bryn Mawr Hospital, Bryn Mawr, Pennsylvania \\ \#Michigan Healthcare Professionals, 21st Century Oncology, Farmington Hills, Michigan \\ ${ }^{* *}$ Imperial College, London, United Kingdom \\ t†Virginia Commonwealth University, Massey Cancer Center, Richmond, Virginia \\ ¥¥leveland Clinic Cancer Center, Cleveland, Ohio \\ $\S$ Arizona Breast Cancer Specialists, Scottsdale, Arizona
}

\begin{abstract}
Purpose: Shorter courses of accelerated partial-breast irradiation delivered as single-fraction intraoperative therapy are now offered as an alternative to 4 to 6 weeks of whole-breast irradiation after lumpectomy. However, this approach has potential shortcomings in patient selection and target volume definition and in dosimetric, radiobiological, and logistical issues. We designed a prospective, phase 2, multi-institution clinical trial to study 2- or 3-day accelerated partial breast irradiation delivered with brachytherapy applicators.
\end{abstract}

Methods and Materials: This trial treats select breast cancers after breast-conserving surgery with brachytherapy applicators that deliver $22.5 \mathrm{~Gy}$ in 3 fractions of $7.5 \mathrm{~Gy}$. The planning treatment volume was 1 to $1.5 \mathrm{~cm}$ beyond the surgical cavity. Eligible women were aged $\geq 45$ years with unicentric invasive or in situ tumors $\$ 3.0 \mathrm{~cm}$ with positive estrogen or progesterone receptors

Reprint requests to: Atif J. Khan, MD, Memorial Sloan Kettering Cancer Center, Department of Radiation Oncology, 1275 York Ave, New York, NY 10065. Tel: (848) 225-6334; khana7@ mskcc.org.

NCI/ClinicalTrials.gov identifier: NCT02526498.

Conflict of interest: C.Y. is on the advisory board of Cianna Medical but is not compensated. 
and no metastasis to axillary nodes that have been excised with negative margins. Strict dosimetric parameters were required to be met before acceptance into the trial.

Results: A group of 200 patients was prospectively enrolled and followed for a minimum of 6 months. Two- or 3-day brachytherapy was associated with low acute or subacute toxicity, $97.25 \%$ excellent or good cosmetic outcomes, and excellent local control in select breast cancers.

Conclusions: Ultrashort breast brachytherapy is dosimetrically feasible and can be delivered with excellent short-term tolerance and low toxicity.

\section{Introduction}

Breast conservation therapy (BCT) results in survival rates equal to those of mastectomy in women with early-stage breast cancer. ${ }^{1-5}$ Adjuvant radiation therapy (RT) is a necessary component of $\mathrm{BCT}$ and is associated with a modest improvement in breast cancer mortality. Although the original BCT studies used whole-breast irradiation (WBI), consensus statements from the American Society of Radiation Oncology and others ${ }^{6,7}$ support accelerated partial breast irradiation (APBI) as a standard-of-care option in selected women with early-stage breast cancer.

Modern brachytherapy with appropriate selection criteria was the first method introduced for APBI. ${ }^{8}$ Initially, the treatment was given with low-dose-rate seeds or strands of ${ }^{192}$ Ir while the patient was in isolation in a shielded hospital room. High-dose-rate brachytherapy with a remote afterloader allowed twice-daily treatments that average 7 to 15 minutes for each session, all delivered as outpatient treatment. Since then, there have been single-institution studies, ${ }^{9-14}$ registry trial data, ${ }^{15,16}$ and a prospective phase 2 cooperative group trial (RTOG 95-17), ${ }^{17}$ all of which have provided evidence for brachytherapy APBI as an equivalent to the historical standard of whole-breast radiation therapy. A large, well-designed, maturely reported European randomized trial (GEC-ESTRO) demonstrated noninferiority of interstitial brachytherapy APBI compared with standard WBI. ${ }^{18}$

An alternate modality of APBI is to deliver a single fraction of RT intraoperatively after partial mastectomy. The TARGIT-A trial reported results with this approach using a spherical applicator to deliver a single dose of $20 \mathrm{~Gy}$ at the applicator surface with $50 \mathrm{kV} \mathrm{X}$ rays, ${ }^{19}$ which delivered approximately 5 to $6 \mathrm{~Gy}$ at a $1-\mathrm{cm}$ depth into tissue. In the Italian approach to intraoperative RT, a single intraoperative fraction of $21 \mathrm{~Gy}$ is delivered using high-energy electrons. ${ }^{20}$ The ELIOT trial randomized patients between intraoperative electrons and WBI. With a median follow-up of 5.8 years, the ipsilateral in-breast recurrence rate was $5.3 \%$ for the intraoperative electron group versus $0.7 \%$ for the whole-breast radiation therapy group, which represented a statistically significant difference. Similarly, the TARGIT trial randomized patients between whole-breast and intraoperative electronic brachytherapy and, at a median follow-up of 29 months, the difference in breast recurrence rate was $1.3 \%$ versus $3.3 \%$, also a statistically significant difference. For the TARGIT trial, insufficient dose may be the likely explanation, whereas for the ELIOT trial, the higher-risk patient population probably factored into the difference. 
We initiated a multi-institutional prospective trial to study an abbreviated APBI schedule delivered with brachytherapy applicators: the original and most mature modality for APBI. This article describes our first results in 200 prospectively studied patients treated with this novel schedule. Our hypothesis was that a 3-fraction schedule would result in toxicity, cosmetic outcomes, and local control similar to those in published reports with conventional 5- to 6-week WBI and 7- to 10-fraction APBI.

\section{Methods and Materials}

Between September 2015 and August 2017, 200 women were entered into a multicenter, prospective, phase 2 clinical trial after signing informed consent. The study was approved by the institutional review board (IRB). Eight institutions were invited to participate based on their experience in delivering APBI. This study was supported by an unrestricted research grant from Cianna Medical and Elekta, who had no control over the selection of institutions or data analysis.

Three breast brachytherapy techniques were allowed: multicatheter interstitial brachytherapy and 2 commonly used single-entry devices (the multilumen Strut Adjusted Volume Implant [SAVI] device [Cianna Medical, Alisa Viejo, CA] and the multilumen Contura device by Hologic [CA]). Interstitial brachytherapy catheters were individually inserted $1.5 \mathrm{~cm}$ beyond and within the surgical cavity. The SAVI device has a fixed central catheter and additional peripheral source lumens that are expanded to be in direct contact with the surgical cavity edge. It comes in 4 sizes, with 6,8 , or 10 peripheral struts in addition to the central one. The Contura is a balloon brachytherapy catheter with a central lumen and 4 additional lumens offset by $5 \mathrm{~mm}$ from the central lumen. These multilumen devices allow for treatmentplanning optimization well beyond what is achievable by single-lumen devices, such as the original MammoSite balloon catheter. Figure 1 shows representative axial treatmentplanning images for each technique.

We wanted to deliver the entire course of adjuvant RT in 2 or 3 days. This abbreviated regimen allows for a woman and her supporting companions to travel from remote or underserved areas to a treatment facility and complete an entire course of adjuvant RT with just a single overnight stay or a stay of 2 nights. Shortening the brachytherapy to 2 or 3 days is an obvious convenience factor for women because the treatment does not extend over a weekend. In a 3-fraction schedule, catheters or devices could be placed in the morning on day 1 . Allowing ample time for treatment planning, fraction 1 treatment could be given that afternoon, followed by fractions 2 and 3 the next day, separated in time by 6 to 8 hours. We hypothesize that these shorter schedules may increase access to adjuvant breast RT and, by extension, to BCT in regions with limited RT resources.

\section{Radiobiological rationale}

We now have the most robust in-human clinical data set on the radiobiological parameters in breast cancer; these data confirm the low $\alpha$-to- $\beta$ ratio for breast cancer. As such, the fraction sensitivity of breast cancer can be exploited with higher fraction sizes, resulting in more compressed treatment times. ${ }^{21}$ However, care must be taken to not exceed the tolerance of 
normal tissues. For our effort, we were particularly interested in radiobiological modeling that was accurate and based on current radiobiological parameters. A renowned radiobiologist with several decades of modeling in breast cancer was recruited as a coinvestigator (R.D.).

We used 50 Gy delivered in 2-Gy fractions as our reference schedule, which is radiobiologically equivalent to $34 \mathrm{~Gy}$ in $3.4 \mathrm{~Gy}$ twice daily, the most common APBI schedule. Assuming tumor parameters of $\alpha$-to- $\beta=4 \mathrm{~Gy}$ and $\alpha=0.27 \mathrm{~Gy}^{-1}$, if repopulation effects are disregarded, a reference schedule of 50 Gy in 25 fractions delivers a tumor biologically effective dose (BED) of $75.0 \mathrm{~Gy}_{4}$. Wyatt et $\mathrm{al}^{22}$ have reviewed postoperative repopulation parameters in breast cancer and used working values of effective doubling time $\mathrm{T}_{\text {eff }}=26$ days and delay time $=0$ days. This method yields a $\mathrm{K}$ factor of $0.693 /\left(a \times \mathrm{T}_{\text {eff }}\right)=$ $0.693 /(0.27 \times 26)=0.1 \mathrm{~Gy} /$ day. A 25 -fraction treatment usually lasts about 32 days; as such, the calculated BED is reduced by $32 \times 0.1=3.2 \mathrm{~Gy}$ (ie, the reference tumor BED, corrected for repopulation, is 75 to $3.2 \sim 71.8 \mathrm{~Gy}_{4}$ ).

The radiobiological influence of the dose gradient across the brachytherapy treatment volume may be accounted for using the analytical method described by Dale et al. ${ }^{23}$ This approach calculates a multiplying factor with which to multiply the prescribed BED (BED prescribed) to take account of the dose gradient effect, the radiosensitivity parameters, the fractional dose, and the number of fractions. The resultant BED (BED actual) is that of the equivalent uniform dose, which would produce the same cell kill as the reference schedule. Acknowledging the potential limitations of the linear quadratic assumptions, the closest results were for $7.25 \mathrm{~Gy} \times 3$ and $7.5 \mathrm{~Gy} \times 3$, with respective multiplying factors of 1.15 and 1.16, leading to BED actuals of 70.8 and $74.3 \mathrm{~Gy}_{4}$, respectively. We chose $7.5 \mathrm{~Gy} \times 3$ as the closest approximation exceeding $71.8 \mathrm{~Gy}_{4}$.

\section{Trial design and patient enrollment}

Eligible patients included women at least 45 years old with small ( $\leq \mathrm{cm}$ ) unifocal invasive or in situ tumors excised with negative margins (no tumor on ink) that are node negative and positive for estrogen receptors or progesterone receptors. The primary objective was to evaluate the toxicity of this regimen. The treatment was to be considered unsafe if a 2-year serious toxicity rate exceeding $10 \%$ could not be excluded with the $95 \%$ confidence interval. Serious toxicity was defined as any toxicity occurring at any time that was greater than grade 2 using National Cancer Institute Common Terminology Criteria for Adverse Events v4.0 criteria. In a cohort of 200 patients, there should be 11 or fewer serious toxicities to exclude a rate of $10 \%$ using the upper limit of the $95 \%$ confidence interval, assuming a true incidence of $3 \%$.

Secondary objectives were to evaluate cosmesis and the actuarial local tumor-control rate and to identify covariates associated with and predictive of poor cosmetic outcome. We expect the 3-year local control rate by the Kaplan-Meier method to be $>95 \%$ (corresponding to a 3-year local failure rate of $5 \%$ or lower). The percentage of patients with good or excellent results at 2 years should exceed $80 \% .^{16,24}$ The study center for data collection and 
statistical analysis was the Rutgers Cancer Institute of New Jersey, Office of Human Research Services.

\section{Treatment planning and delivery}

A minimum of 6 hours was required between dose fractions. Dose was prescribed to target volumes as described in the NSABP-B39/RTOG-0413 trial (1-cm margin from applicator for SAVI/Contura and 1.5-cm margin for interstitial). Dosimetric analysis was to be submitted before the patient could be entered into the trial. Dosimetric criteria were defined as follows: (1) at least $90 \%$ of the target volume (PTV-eval) must be covered by $\geq 0 \%$ of the prescribed dose; (2) the maximum skin and rib dose should not exceed $100 \%$ of the prescribed dose, but a relaxation constraint is permitted up to $120 \%$ if needed to satisfy all dose parameters; (3) the volume of breast tissue receiving $150 \%$ of the prescribed dose (V150) should not exceed $40 \mathrm{~cm}^{3}$; (4) the volume of breast tissue receiving $200 \%$ of the dose should not exceed $17 \mathrm{~cm}^{3}$, with $\triangle 5 \mathrm{~cm}^{3}$ preferred; and (5) for multicatheter interstitial implant, the dose homogeneity index must be at least 0.75 . Skin was defined as on the surface, without any subcutaneous margin. The chest wall was contoured at the pectoralis muscles and excluded from the target volume. Ribs were contoured separately for dose-volume histogram analysis.

The study protocol and the informed consent form for participation were approved by the IRB at the Rutgers Cancer Institute of New Jersey (the lead institution) and met the guidelines for the responsible conduct of clinical research with human subjects. The institutional IRBs at each participating site also completed institutional reviews, as mandated by their regulatory entities.

\section{Statistical methods}

All time intervals were calculated from the start date of radiation treatment. Patients were followed at 2 to 8 weeks, and then at year 1 and year 2; interim unscheduled visits for toxicities were documented. Fisher's exact test will be performed to correlate clinicopathologic covariates with toxicity and with cosmesis, but for this early analysis there were too few events. The association of variables with local recurrence times will be investigated by fitting a parametric model and examining the significance of the parameter estimates. Nonparametric estimates of the survival or recurrence-free distributions or recurrence distribution will be obtained by life table methods. Tests will be declared statistically significant if the calculated $P$ value was $\leq 05$. All tests appear as 2-sided $P$ values.

\section{Results}

In total, 200 patients were enrolled between August 17, 2015, and August 16, 2017. One patient withdrew from the study right after treatment completion. The median follow-up time was 12 months (range, 0.5-25 months). This time reflects the scheduled follow-up intervals, which occurred at 2 to 8 weeks and then at years 1 and 2, with unscheduled visits for toxicity if needed. The median time from treatment to the date of this analysis was 19 months (range, 10-34 months); thus, all patients have been at risk for potential toxicity 
events for at least 10 months. The rate of accrual for this clinical trial was robust (200 patients in 2 years), reflecting patient enthusiasm for a shorter RT treatment duration than either conventional 5 to 6 weeks of external beam WBI or the 7- or 8-day existing 10fraction APBI. Table 1 displays pertinent clinicopathologic variables in the patient population.

Treatment-related information is shown in Table $2 ; 37 \%$ of all patients were treated with multicatheter interstitial implants, and those remaining were treated with one of the singleentry devices. Dosimetric variables in the study population are displayed in Table 3. Dosimetric criteria have been achieved in all but 1 case, in which the V200 was $22 \mathrm{~cm}^{3}$ (upper range of acceptable, $17 \mathrm{~cm}^{3}$ ). The range of skin spacing was 1.3 to $76.4 \mathrm{~mm}$ (median, $8.25 \mathrm{~mm}$; mean, 10.34), and the range of rib spacing was 1.0 to $99.3 \mathrm{~mm}$ (median, $9.45 \mathrm{~mm}$; mean, 15.9). The mean V150 was $24.2 \mathrm{~cm}^{3}$, and the mean $\mathrm{V} 200$ was $10.2 \mathrm{~cm}^{3}$ in the entire cohort.

Acute toxicities were minimal in the study population, and the incidence of toxicities is shown in Table 4. Of the 200 patients, 77 patients (38.5\%) reported any toxicity. Each patient could have more than 1 toxicity; hence, a total of 116 toxicities were described. Most toxicities $(96 \%)$ were grade 1 to 2 , as expected, most of which resolved without intervention. Thirty-one patients $(15.5 \%)$ had radiation dermatitis, of which 4 cases were grade 2 . Three patients had grade 2 breast infections requiring antibiotics. Breast pain was reported in 31 patients, of which 10 cases were grade 2 . Two patients had grade 1 breast edema, and 1 patient had fat necrosis. Seroma formation was noted in 8 patients, of which 2 cases were grade 2 . Twenty-two patients had deep tissue fibrosis, of which 3 cases were grade 2 , and 12 patients had superficial tissue fibrosis, of which 2 cases were grade 2 . Three patients had grade 2 hyperpigmentation.

Of the 3 patients with grade 3 toxicities, 1 patient had grade 3 radiation dermatitis, which completely resolved on 1-year follow-up without intervention. The 2 other patients had nonhealing wounds requiring surgical intervention. One of these 2 patients traveled abroad right after treatment and was found to have erythema and swelling of the treated breast on her 6-month follow-up appointment. She received antibiotics and eventually had an incision and drainage at an institution outside the country. She later required surgical intervention in the United States owing to the lack of healing of the surgical wound. The pathologic findings reported were fat necrosis. At the patient's last follow-up, the wound had healed completely. The second patient also experienced nonhealing of the surgical wound after treatment and required surgical intervention. Pathologic findings from the second surgery revealed foreign body giant cell reaction and a $0.25-\mathrm{mm}$ focus of atypical epithelial cells suspicious for residual invasive ductal carcinoma. The patient healed well, with excellent cosmesis a month after her second surgery. Notably, this patient had history of pustular psoriasis and was an active smoker during treatment.

Baseline aesthetic and functional conditions were collected using the Breast Cancer Treatment Outcome Scale and will be collected for comparison at the 2-year follow-up. Cosmetic outcome by the Harvard Scale was available for 182 patients at last follow-up. At last follow-up, 177 (97.25\%) of the patients had good or excellent cosmesis, and only 1 
patient had poor cosmesis. The analysis of cosmesis by photography will be performed at a later date. Short-term local tumor control was excellent. One patient experienced in-breast tumor recurrence; she was also found to have bone metastasis. Regional nodal failure was seen in 1 patient $(0.005 \%)$. No other recurrence events were reported.

\section{Discussion}

We have demonstrated the safety of delivering 3 fractions compressed APBI, although some local wound issues did occur in a few patients, as can be expected after an invasive technique. We also have demonstrated, perhaps for the first time, that very tight dosimetric targets of quality can consistently be met in a large cohort of patients treated across multiple institutions. Our reported toxicities are entirely in line with the published experiences of 10fraction brachytherapy-based ABPI.

Our results establish the safety of this compressed brachytherapy schedule regarding acute toxicity. Consistent with other modalities of adjuvant RT, 77 patients (38.5\%) reported any toxicity. Most toxicities (96\%) were grade 1 to 2, as expected, and most resolved without intervention. For our primary endpoint analysis, grade 3 toxicity was reported in $1.5 \%$ of the study population (3 patients), which was well within the predefined upper limit of 11 observed interval, leading to a dose amendment of $18 \mathrm{~Gy}$, after which fewer complications were noted.

In a similar phase 1 study of 28 patients at the University of Virginia, an intraoperative multilumen balloon applicator was implanted intraoperatively with subsequent computed tomography-planning and delivery of a single-fraction, monotherapy dose of $12.5 \mathrm{~Gy} .{ }^{27}$ The approach had low serious toxicities. At last follow-up, 177 of enrolled patients had good or excellent cosmesis, and the short-term local control rate was excellent (99\%). The investigation of these abbreviated courses of RT is a rational progression of the clinical literature in APBI.

Furthermore, these shortened courses of RT should not be trivialized as solely a matter of convenience. In a recent Markov simulation of a resource-constrained system with a backlog of demand, utilization of the shortest appropriate schedules could increase the proportion of women alive with a conserved breast by increasing the number of women with access to RT. ${ }^{25}$ We chose participating sites based on established proficiency in brachytherapy because this was a safety study and implant quality was important. We have now established that dosimetric constraints are readily achievable and that the expected outcomes are comparable to those found in control data. Breast brachytherapy as a technique is not difficult and requires simple training.

A handful of prospective studies have attempted to shorten the course of partial-breast RT. Investigators from Memorial Sloan Kettering Cancer Center placed a Silastic applicator (the Harrison-Anderson-Mick, or HAM, applicator) intraoperatively into lumpectomy cavities and delivered a single fraction of $20 \mathrm{~Gy}$ prescribed $1 \mathrm{~cm}$ from the applicator surface. ${ }^{26}$ Five of the first 18 patients developed significant fibrosis and retraction at the 6-month toxicity, and a phase 2 study is ongoing. In a study from the William Beaumont Hospital, 
investigators delivered 28 Gy in 4 fractions over 2 days with a single-lumen MammoSite device. ${ }^{28}$ In 45 treated patients followed for a median of 3.7 years, the investigators reported a low rate of acute toxicities exceeding grade 2 but had perhaps a surprisingly high rate of patients who reported breast pain (26\%). Reported late toxicities included fat necrosis in 13 patients (29\%) and rib fractures in 3 patients; these outcomes appear to be higher than usual and likely resulting from the optimization inflexibility of single-lumen devices.

Although our initial results are encouraging, we acknowledge that additional follow-up will be necessary to establish the true safety and efficacy of this extremely hypofractionated course of treatment. The time cycles for the development of treatment-related toxicities after brachytherapy can be variable and delayed, as demonstrated by Chen et $\mathrm{al}^{29}$ and also by Wazer et al. ${ }^{30}$ In perhaps the most vivid demonstration of late-onset toxicities, Hattangadi and colleagues at Massachusetts General Hospital reported moderate or severe fibrosis in $>50 \%$ of patients, fat necrosis in $35 \%$, and $>1 \mathrm{~cm}^{2}$ telangiectasias in $35 \%$ in their 50-patient, prospectively studied cohort treated with low dose rate interstitial APBI and followed for a median of 134 months. ${ }^{10}$

However, it is equally important to remember that these reports are from what is effectively an entirely different era of quality control and treatment planning sophistication. We remain optimistic that advances in treatment applicators and in treatment-planning and delivery methodologies in the intervening decades since those preliminary reports should mitigate against the inconsistencies in implant quality and techniques. We fully expect these technological improvements to lead to improvements in clinical outcomes.

\section{Conclusions}

Brachytherapy APBI by 3 catheter methods, using an ultrashort schedule of $22.50 \mathrm{~Gy}$ in 3 fractions of $7.50 \mathrm{~Gy}$ each given over 2 or 3 days, provides acceptable acute and subacute toxicity, a high percentage of excellent and good cosmetic outcomes, and excellent shortterm tumor control rates.

\section{Acknowledgments}

This investigator-initiated trial was sponsored by the Rutgers Cancer Institute of New Jersey, with partial support from Cianna Medical and Elekta.

\section{References}

1. Clark RM, Whelan T, Levine M, et al. Randomized clinical trial of breast irradiation following lumpectomy and axillary dissection for node-negative breast cancer: An update. Ontario Clinical Oncology Group. J Natl Cancer Inst 1996;88:1659-1664. [PubMed: 8931610]

2. Fisher B, Jeong JH, Anderson S, et al. Twenty-five-year follow-up of a randomized trial comparing radical mastectomy, total mastectomy, and total mastectomy followed by irradiation. N Engl J Med 2002;347: 567-575. [PubMed: 12192016]

3. Liljegren G, Holmberg L, Adami HO, et al. Sector resection with or without postoperative radiotherapy for stage I breast cancer: Five-year results of a randomized trial. Uppsala-Orebro Breast Cancer Study Group. J Natl Cancer Inst 1994;86:717-722. [PubMed: 8158702] 
4. Veronesi U, Cascinelli N, Mariani L, et al. Twenty-year follow-up of a randomized study comparing breast-conserving surgery with radical mastectomy for early breast cancer. N Engl J Med 2002;347:1227-1232. [PubMed: 12393819]

5. Clark RM, McCulloch PB, Levine MN, et al. Randomized clinical trial to assess the effectiveness of breast irradiation following lumpectomy and axillary dissection for node-negative breast cancer. $\mathrm{J}$ Natl Cancer Inst 1992;84:683-689. [PubMed: 1314910]

6. Correa C, Harris EE, Leonardi MC, et al. Accelerated partial breast irradiation: Executive summary for the update of an ASTRO Evidence-Based Consensus Statement. Pract Radiat Oncol 2017;7:7379. [PubMed: 27866865]

7. Shah C, Vicini F, Shaitelman SF, et al. The American Brachytherapy Society consensus statement for accelerated partial-breast irradiation. Brachytherapy 2018;17:154-170. [PubMed: 29074088]

8. King TA, Bolton JS, Kuske RR, et al. Long-term results of wide-field brachytherapy as the sole method of radiation therapy after segmental mastectomy for T(is,1,2) breast cancer. Am J Surg 2000;180:299-304. [PubMed: 11113440]

9. Arthur DW, Koo D, Zwicker RD, et al. Partial breast brachytherapy after lumpectomy: Low-doserate and high-dose-rate experience. Int J Radiat Oncol Biol Phys 2003;56:681-689. [PubMed: 12788173]

10. Hattangadi JA, Powell SN, MacDonald SM, et al. Accelerated partial breast irradiation with lowdose-rate interstitial implant brachytherapy after wide local excision: 12-year outcomes from a prospective trial. Int J Radiat Oncol Biol Phys 2012;83:791-800. [PubMed: 22099046]

11. Ott OJ, Hildebrandt G, Potter R, et al. Accelerated partial breast irradiation with interstitial implants: Risk factors associated with increased local recurrence. Int J Radiat Oncol Biol Phys 2011;80: 1458-1463. [PubMed: 20675064]

12. Polgar C, Strnad V, Major T. Brachytherapy for partial breast irradiation: The European experience. Semin Radiat Oncol 2005;15:116-122. [PubMed: 15809937]

13. Vicini FA, Kestin L, Chen P, et al. Limited-field radiation therapy in the management of early-stage breast cancer. J Natl Cancer Inst 2003; 95:1205-1210. [PubMed: 12928345]

14. Wazer DE, Berle L, Graham R, et al. Preliminary results of a phase I/II study of HDR brachytherapy alone for T1/T2 breast cancer. Int J Radiat Oncol Biol Phys 2002;53:889-897. [PubMed: 12095554]

15. Arthur DW, Vicini FA, Todor DA, et al. Improvements in critical dosimetric endpoints using the Contura multilumen balloon breast brachytherapy catheter to deliver accelerated partial breast irradiation: Preliminary dosimetric findings of a phase IV trial. Int J Radiat Oncol Biol Phys 2011;79:26-33. [PubMed: 20378268]

16. Shah C, Badiyan S, Ben Wilkinson J, et al. Treatment efficacy with accelerated partial breast irradiation (APBI): Final analysis of the American Society of Breast Surgeons MammoSite((R)) breast brachytherapy registry trial. Ann Surg Oncol 2013;20:3279-3285. [PubMed: 23975302]

17. Arthur DW, Winter K, Kuske RR, et al. A phase II trial of brachytherapy alone after lumpectomy for select breast cancer: Tumor control and survival outcomes of RTOG 95-17. Int J Radiat Oncol Biol Phys 2008;72:467-473. [PubMed: 18294778]

18. Strnad V, Ott OJ, Hildebrandt G, et al. 5-year results of accelerated partial breast irradiation using sole interstitial multicatheter brachytherapy versus whole-breast irradiation with boost after breastconserving surgery for low-risk invasive and in-situ carcinoma of the female breast: A randomised, phase 3, non-inferiority trial. Lancet 2016;387:229-238. [PubMed: 26494415]

19. Vaidya JS, Wenz F, Bulsara M, et al. Risk-adapted targeted intraoperative radiotherapy versus whole-breast radiotherapy for breast cancer: 5-year results for local control and overall survival from the TARGIT-A randomised trial. Lancet 2014;383:603-613. [PubMed: 24224997]

20. Veronesi U, Orecchia R, Maisonneuve P, et al. Intraoperative radiotherapy versus external radiotherapy for early breast cancer (ELIOT): A randomised controlled equivalence trial. Lancet Oncol 2013;14: 1269-1277. [PubMed: 24225155]

21. Owen J, Ashton A, Bliss J, et al. Effect of radiotherapy fraction size on tumor control in patients with early-stage breast cancer after local tumour excision: Long-term results of a randomised trial. Lancet Oncol 2006;7:467-471. [PubMed: 16750496] 
22. Wyatt R, Jones B, Dale R. Radiotherapy treatment delays and their influence on tumour control achieved by various fractionation schedules. Br J Radiol 2008;81:549-563. [PubMed: 18378526]

23. Dale R, Coles I, Deehan C, et al. Calculation of integrated biological response in brachytherapy. Int J Radiat Oncol Biol Phys 1997;38:633-642. [PubMed: 9231690]

24. Whelan TJ, Pignol JP, Levine MN, et al. Long-term results of hypofractionated radiation therapy for breast cancer. N Engl J Med 2010; 362:513-520. [PubMed: 20147717]

25. Khan AJ, Rafique R, Zafar W, et al. Nation-scale adoption of shorter breast radiation therapy schedules can increase survival in resource constrained economies: Results from a Markov chain analysis. Int J Radiat Oncol Biol Phys 2017;97:287-295. [PubMed: 27986343]

26. Beal K, McCormick B, Zelefsky MJ, et al. Single-fraction intraoperative radiotherapy for breast cancer: Early cosmetic results. Int J Radiat Oncol Biol Phys 2007;69:19-24. [PubMed: 17446003]

27. Showalter SL, Petroni G, Trifiletti DM, et al. A novel form of breast intraoperative radiation therapy with CT-guided high-dose-rate brachytherapy: Results of a prospective phase 1 clinical trial. Int J Radiat Oncol Biol Phys 2016;96:46-54. [PubMed: 27511846]

28. Wilkinson JB, Martinez AA, Chen PY, et al. Four-year results using balloon-based brachytherapy to deliver accelerated partial breast irradiation with a 2-day dose fractionation schedule. Brachytherapy 2012;11:97-104. [PubMed: 21727032]

29. Chen PY, Vicini FA, Benitez P, et al. Long-term cosmetic results and toxicity after accelerated partial-breast irradiation: A method of radiation delivery by interstitial brachytherapy for the treatment of early-stage breast carcinoma. Cancer 2006;106:991-999. [PubMed: 16421922]

30. Wazer DE, Kaufman S, Cuttino L, et al. Accelerated partial breast irradiation: An analysis of variables associated with late toxicity and long-term cosmetic outcome after high-dose-rate interstitial brachytherapy. Int J Radiat Oncol Biol Phys 2006;64: 489-495. [PubMed: 16246495] 


\section{Summary}

Intraoperative radiation therapy for early-stage breast cancer offers convenience but is problematized by a lack of postpathology patient selection. We report preliminary results from a novel fractionation scheme that condenses accelerated partial breast irradiation to 2 or 3 days. The treatment as delivered is well tolerated and has low toxicity. This approach mimics the convenience of intraoperative radiation therapy without its limitations. 


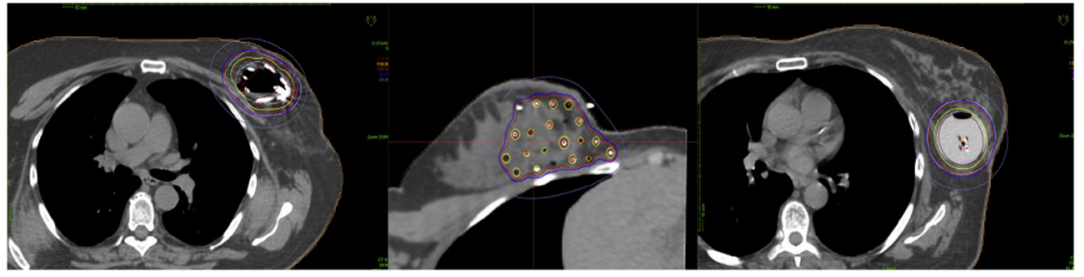

Fig. 1.

Representative axial images from each of the 3 techniques allowed on the TRIUMPH-T trial. The left panel shows a Strut Adjusted Volume Implant applicator, the middle panel shows a multicatheter interstitial implant, and the right panel shows a Contura multilumen applicator. 


\section{Table 1}

Patient and clinical-pathologic characteristics $(\mathrm{N}=200)$

\begin{tabular}{|c|c|}
\hline Characteristic & Result \\
\hline \multicolumn{2}{|l|}{ Follow-up, mo } \\
\hline Median * (range) & 19 [10-34] \\
\hline \multicolumn{2}{|l|}{ Age, y } \\
\hline Median (range) & $65[48-88]$ \\
\hline Characteristic & No. $(\%)$ \\
\hline \multicolumn{2}{|l|}{ Race } \\
\hline White & $174(87)$ \\
\hline Asian & $7(3.5)$ \\
\hline African American & $7(3.5)$ \\
\hline Indian American & $1(0.5)$ \\
\hline Hispanic & $11(5.5)$ \\
\hline \multicolumn{2}{|l|}{ Breast cup size } \\
\hline $\mathrm{A}$ & $4(2)$ \\
\hline B & $30(15)$ \\
\hline $\mathrm{C}$ & $50(25)$ \\
\hline $\mathrm{D}+$ & $69(34.5)$ \\
\hline Not measured & $47(23.5)$ \\
\hline \multicolumn{2}{|l|}{ Lesion location } \\
\hline UIQ & $32(16)$ \\
\hline LIQ & $16(8)$ \\
\hline Central & $26(13)$ \\
\hline UOQ & $102(51)$ \\
\hline LOQ & $11(5.5)$ \\
\hline Missing & $13(6.5)$ \\
\hline \multicolumn{2}{|l|}{ Histology } \\
\hline DCIS & $28(14)$ \\
\hline Invasive ductal & 157 (78.5) \\
\hline Invasive lobular & $14(7)$ \\
\hline Mixed invasive & $1(0.5)$ \\
\hline \multicolumn{2}{|l|}{ Tumor size, mm } \\
\hline Median, [range] & $10,[1-28]$ \\
\hline$<5$ & $17(8.5)$ \\
\hline 25 to $<10$ & $72(36)$ \\
\hline$\geq 10$ to $\_0$ & $95(47.5)$ \\
\hline$>20$ & $14(7)$ \\
\hline Unknown & $2(1)$ \\
\hline \multicolumn{2}{|l|}{ AJCC $\mathrm{T}$ tumor status } \\
\hline Tis & $28(14)$ \\
\hline $\mathrm{T} 1$ & $158(79)$ \\
\hline
\end{tabular}

Int J Radiat Oncol Biol Phys. Author manuscript; available in PMC 2020 July 21. 


\begin{tabular}{cc}
\hline Characteristic & Result \\
\hline $\mathrm{T} 2, \unlhd \mathrm{cm}$ & $13(6.5)$ \\
$\mathrm{T} 2,>3 \mathrm{~cm}$ & $1(0.5)$ \\
Margins & \\
Negative & $184(92)$ \\
Close $(<2 \mathrm{~mm})$ & $16(8)$ \\
Positive & $0(0)$ \\
Estrogen receptor & \\
Positive & $196(98)$ \\
Negative & $4(2)$ \\
Progesterone receptor & \\
Positive & $179(89.5)$ \\
Negative & $20(10)$ \\
Unknown & $1(0.5)$ \\
Her2neu & \\
Positive & $8(4)$ \\
Negative & $158(79)$ \\
Equivocal & $5(2.5)$ \\
Not done & $29(14.5)$ \\
\hline
\end{tabular}

Abbreviations: AJCC = American Joint Committee on Cancer; DCIS = ductal carcinoma in situ; LIQ = lower inner quadrant; LOQ = lower outer quadrant; Tis = in situ carcinoma; UIQ = upper inner quadrant; UOQ = upper outer quadrant.

Median follow-up calculated from treatment to date of current analysis. 


\section{Table 2}

\section{Treatment characteristics}

\begin{tabular}{lc}
\hline \multicolumn{1}{c}{ Characteristic } & Result \\
\hline Surgery to RT time, d & \\
Mean (std) & $28(16)$ \\
Median & 27 \\
Range & {$[2-98]$} \\
Characteristic, n (\%) & \\
Axillary dissection & \\
SLN Bx & $172(86)$ \\
ALD & $3(1.5)$ \\
None (all DCIS) & $22(11)$ \\
Adjuvant treatment & \\
Hormone & $178(89)$ \\
Chemotherapy & $5(2.5)$ \\
Both & $5(2.5)$ \\
None & $10(5)$ \\
Missing & $2(1)$ \\
CED used & $15(7.5)$ \\
Device used & \\
SAVI 6-1 mini & $21(10.5)$ \\
SAVI 6-1 & $20(10.0)$ \\
SAVI 8-1 & $39(19.5)$ \\
SAVI 10-1 & $21(10.5)$ \\
Contura 4-5 cm & $19(9.5)$ \\
Contura 5-6 cm & $6(3.0)$ \\
Multicatheter & $74(37.0)$ \\
\hline & \\
& \\
&
\end{tabular}

Abbreviations: $\mathrm{ALD}=$ Axillary lymph node dissection; $\mathrm{CED}=$ Cavity evaluation device; $\mathrm{DCIS}=$ ductal carcinoma in situ; $\mathrm{RT}=$ radiation therapy; SAVI = Strut Adjusted Volume Implant; SLN Bx = sentinel lymph node biopsy; std = standard deviation . 


\section{Table 3}

Dosimetric and geometric outcomes in initial cohort $(\mathrm{N}=200)$

\begin{tabular}{|c|c|}
\hline Characteristic & Result \\
\hline \multicolumn{2}{|c|}{ Minimum skin spacing, $\mathrm{mm}$} \\
\hline Mean (std) & $10.34(8.8)$ \\
\hline Median & 8.25 \\
\hline Range & {$[1.3-76.4]$} \\
\hline \multicolumn{2}{|c|}{ Minimum rib spacing, $\mathrm{mm}$} \\
\hline Mean (std) & $15.0(15.9)$ \\
\hline Median & 9.45 \\
\hline Range & [1.0-99.3] \\
\hline \multicolumn{2}{|c|}{ Skin dose, $\%$ of PD } \\
\hline Median & 80 \\
\hline Range & [20.8-113] \\
\hline \multicolumn{2}{|c|}{ Rib dose, $\%$ of PD } \\
\hline Median & 75 \\
\hline Range & [0-114.2] \\
\hline \multicolumn{2}{|l|}{$\mathrm{V} 100, \mathrm{~cm}^{3}$} \\
\hline Mean (std) & $89.5(54.6)$ \\
\hline Median & 77.45 \\
\hline Range & [4.95-349.9] \\
\hline \multicolumn{2}{|l|}{$\mathrm{V} 150, \mathrm{~cm}^{3}$} \\
\hline Mean (std) & $24.2(8.6)$ \\
\hline Median & 24.6 \\
\hline Range & {$[0-39.6]$} \\
\hline \multicolumn{2}{|l|}{$\mathrm{V} 200, \mathrm{~cm}^{3}$} \\
\hline Mean (std) & $10.2(4.2)$ \\
\hline Median & 10.3 \\
\hline Range & {$[0-22.3]$} \\
\hline \multicolumn{2}{|c|}{$\%$ PD to $100 \%$ of PTV eval } \\
\hline Mean (std) & $71.1(13.3)$ \\
\hline Median & 72.05 \\
\hline Range & {$[0-97.3]$} \\
\hline \multicolumn{2}{|c|}{$\% \mathrm{PD}$ to $95 \%$ of PTV eval } \\
\hline Mean (std) & $93.3(9.2)$ \\
\hline Median & 94.8 \\
\hline Range & {$[0-106]$} \\
\hline \multicolumn{2}{|c|}{$\%$ PD to $90 \%$ of PTV eval } \\
\hline Mean (std) & $99.1(5.4)$ \\
\hline Median & 99.75 \\
\hline Range & [82-111] \\
\hline
\end{tabular}

Volume of PTV eval, $\mathrm{cm}^{3}$ 


\begin{tabular}{lc}
\hline Characteristic & Result \\
\hline Mean (std) & $97.1(55.5)$ \\
Median & 84.96 \\
Range & {$[16.7-386.1]$} \\
\hline
\end{tabular}

Abbreviations: $\mathrm{PD}$ = prescription dose PTVeval = planning target volume as defined in NSABPB39/RTOG0413; std = standard deviation; V100 = volume of breast tissue receiving $100 \%$ of the prescribed dose; V150 $=$ volume of breast tissue receiving $150 \%$ of the prescribed dose; V200 $=$ volume of breast tissue receiving $200 \%$ of the prescribed dose. 


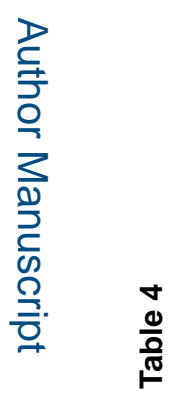

을

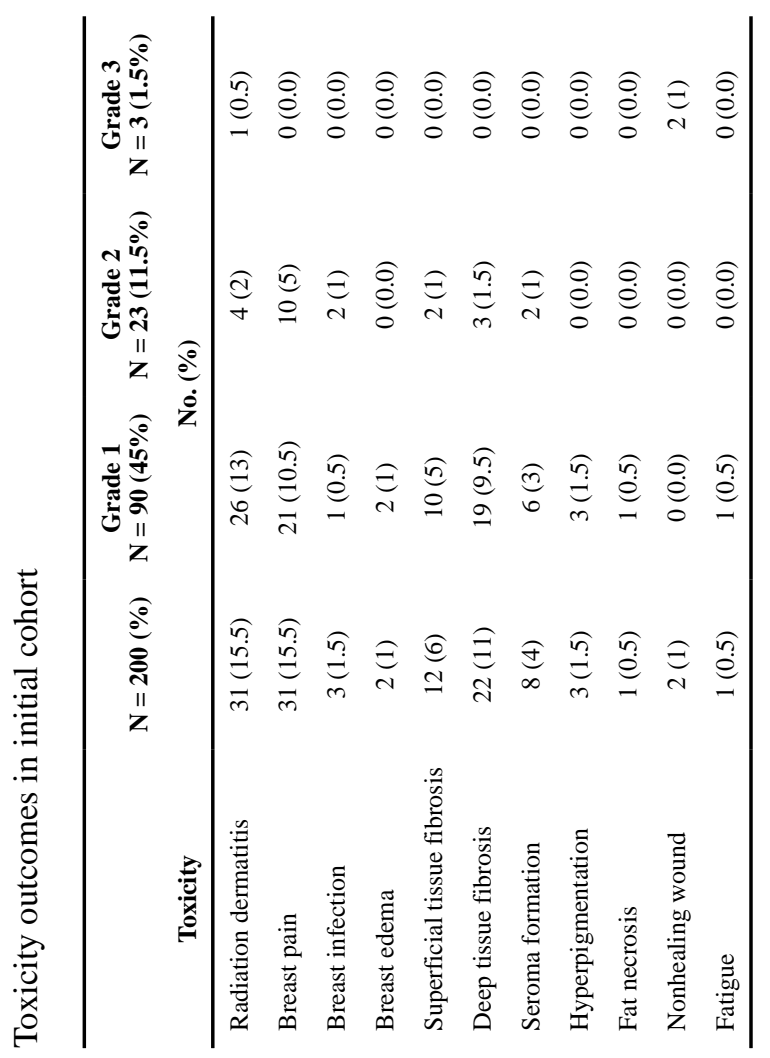

Int J Radiat Oncol Biol Phys. Author manuscript; available in PMC 2020 July 21. 